\title{
0333 LONG-TERM CONSEQUENCE OF INJURY ON SELF-RATED HEALTH
}

B Laursen*, H Müller Correspondence: National Institute of Public Health, University of Southern Denmark, ster Farimagsgade 5A, 2. DK-1353 Copenhagen K, DK-1353, Denmark

10.1136/ip.2010.029215.333

Background Knowledge on long-term consequences of injury on health is vital when injury prevention policies and emergency care are planned. However, few studies have described lasting health consequences associated with injury. This study analyses the relationship between injury and self-assessed health up to ten years postinjury.

Methods The study makes use of health interview survey information linked with data from hospital registries. Using this database the health of a group of Danish injury patients involved in accidents during 1995-2005 was compared to a non-injured group up to 10 years postinjury. The association between self-assessed general health and self-reported depression and injury-related factors was estimated using logistic regression.

Results The ORs of poor self-assessed general health and selfreported depression were 1.83 (CI 1.53 to 2.19) and 1.33 (1.14 to 1.54 ), respectively, among injury patients compared to noninjured. Though decreasing with time, the effect of injury on general health was significant up to 10 years after the injury. The injury type was significantly related to health, with back, head and neck patients reporting poor general health in particular. No gender differences were found in the effect of injury on self-assessed health.

Conclusions Injuries have lasting consequences for physical and mental health up to 10 years after the injury event, in particular for people sustaining head, neck and back injuries. Sustaining an injury has the same effect on general health in men and women. 